Language and Cognition 7 (2015), 563-588. doi:10.1017/langcog.2015.23

(C) UK Cognitive Linguistics Association, 2015

\title{
Conversation, Construction Grammar, and cognition
}

\author{
KERSTIN FISCHER* \\ University of Southern Denmark
}

(Received 09 February 2012 - Revised 26 February 2013 - Accepted 15 March 2013)

\section{A BSTRACT}

Recent developments in grammatical theory seem to invite an integration of grammar and interaction; nevertheless, there are reservations on both sides. While some of these reservations can be traced to misconceptions, others are deeply rooted in the theoretical premises of each approach. The differences are, however, not very well understood; especially theoretical premises regarding the role of cognition in language use have been hindering a fruitful collaboration. Reinterpreting the results of Conversation Analysis (CA; cf. Sacks, Schegloff, \& Jefferson, 1974; Sacks, 1992) in terms of Construction Grammar (Goldberg, 1995, 2006; Croft, 2001, Langacker, 2008) recasts the discursive practices identified in CA in terms of participants' cognitive construals of the communicative situation, making the speaking subjects apparent in their strategies and conceptualizations of the interaction.

K E Y W O R D s : Construction Grammar, Conversation Analysis, cognition, discourse particles.

\section{Introduction}

The extent to which grammar and interaction can be combined depends on the general aims of the respective grammatical theories under consideration; yet recent developments in syntactic theory seem to invite their integration. For instance, many recent approaches to grammar (e.g., Goldberg, 2006; Bresnan, 2007; Bybee, 2007; Langacker, 2008) assume that linguistic knowledge is usage-based, i.e., the result of repeated exposure to the usage of language in context. This assumption not only understands grammatical knowledge to consist of units that "emerge via the progressive entrenchment of configurations

[*] I am very grateful to Laura Michaelis and Elisabeth Reber for their highly insightful and thorough comments. Any possible remaining errors or inconsistencies are, of course, mine. I am also grateful to the Danish Velux Foundation, whose generous funding made this research possible. Address for correspondence: Department of Design and Communication, University of Southern Denmark, 6400 Sonderborg, Denmark. e-mail: kerstin@sdu.dk 
that recur in a sufficient number of events to be established as cognitive routines" (Langacker, 2008, p. 220), but also moves the focus towards actual contexts of use, including interactional contexts.

Furthermore, recent years have seen an increasing integration of linguistic features on all levels of linguistic description, moving away from approaches in which syntax is understood to be autonomous and towards more comprehensive approaches, including even pragmatic information (e.g., Kay, 1995, 2006; Michaelis \& Lambrecht, 1996). Especially the central theoretical assumptions of Construction Grammar offer a unified framework to account for the syntactic, semantic, phonological, and pragmatic properties of utterances (cf. Fillmore, Kay, \& O’Connor, 1988). Construction Grammar thus seems to provide a unique opportunity to consider interactional structures in grammatical terms.

Construction grammarians assume that all linguistic knowledge is essentially sign-based. In contrast to rule-based approaches to grammar, in which grammatical knowledge is largely independent of meaning, Construction Grammar holds that grammatical knowledge consists of form-meaning pairs, the so-called 'constructions'. These pairs may exhibit varying degrees of schematicity, ranging from lexically specific to fully schematic (e.g., Goldberg, 2006 , p. 5), on all linguistic levels. Since thus both words and grammatical constructions are signs and may incorporate both idiosyncratic and schematic properties, grammar and lexicon form a continuum. Construction Grammar is furthermore surface-oriented (Goldberg, 2009) and concentrates on patterns that are either highly entrenched (Goldberg, 2006, p. 5) or exhibit noncompositional properties (Goldberg, 1995, p. 4; Kay \& Fillmore, 1999).

Moreover, Construction Grammar assumes a very broad definition of meaning, including literal (i.e., propositional) meaning, argument structural meaning, conventional implicatures and pragmatic presuppositions, illocutionary forces, and metalinguistic comments (see Kay \& Michaelis, 2012). In addition, numerous interactional studies have meanwhile revealed interactionally relevant meanings of certain constructions, extending the traditional view of meaning embraced in Construction Grammar, which relies heavily on frame semantics (Fillmore, 1976; Fillmore \& Atkins, 1992; Kay \& Fillmore, 1999), to interactional functions (e.g., Thompson \& Couper-Kuhlen, 2005, Hopper \& Thompson, 2008). Construction Grammar thus seems to be generally very well suited to integrate interactional phenomena (cf. also Deppermann, 2007).

The compatibility of Construction Grammar with interactional approaches crucially depends, however, on the version of Construction Grammar under consideration. In particular, the more formally oriented Sign-Based Construction Grammar (Sag, 2007), as well as its precursors (Kay \& Fillmore, 1999), shares the goal with generative grammars (Chomsky, 1965) that a grammar has to provide observational and descriptive adequacy by accounting for the possible 
sentences of a language and only those (Kay, 1995, p. 171). In contrast, Cognitive Grammar (e.g., Langacker, 1987, 2008), Radical Construction Grammar (Croft, 2001), and the Cognitive Construction Grammar approach inspired by Lakoff (1987) and developed by Goldberg $(1995,2006)$ are not mainly concerned with generating grammatically correct sentences and instead aim to describe real speakers' linguistic behaviour and to develop psycholinguistically plausible models of linguistic knowledge, accounting for linguistic creativity and language change as well as for contextual appropriateness. It is thus especially the latter, cognitive linguistic approach which involves networks of more or less entrenched constructions of varying degrees of schematicity that reveals fertile ground for interactionalists' concerns (cf. Deppermann, 2007).

Assuming that the integration of grammatical and interactional knowledge is desirable, for instance for reasons of realistic coverage, and given the possibilities Construction Grammar seems to present for such an integration, the question arises why grammarians do not eagerly incorporate findings from interaction studies, and conversely, why interactionalists do not readily create grammatical representations to present their findings. The reason is that there are many reservations on both sides. From the perspective of the grammarian, many mechanisms of grammar formalization and theory rely on notions like sentence-hood, well-formedness, and semantic completeness, none of which plays an important role in spontaneous interaction. First, spoken interaction is always situated and thus influenced by the contingencies of the situation, which means for linguistic expressions that they are highly context-dependent. Second, the underlying unit in talk-in-interaction is not the sentence but the turn-constructional unit (TCU; see Schegloff, 1996). If, however, the well-formed sentence does not constitute the major point of orientation in grammatical description, much of what syntactic theory has achieved over the past fifty years is called into question. Furthermore, even though many recent studies of interactional phenomena include notions like TCU or transition-relevance place (TRP) (Sacks et al., 1974), even in semiformalized descriptions (e.g., Fischer, 2000; Fried \& Östman, 2005; Wide, 2009), these are not formalized notions at all (cf. Ford, Fox, \& Thompson, 1996; Ford, 2004). Therefore, they cannot play the role the notion of sentence plays in grammars oriented toward written language. Thus, from the perspective of grammatical theory, there are numerous obstacles involved.

Also, from the perspective of conversation analysis, there are several major reservations concerning a grammatical account of interactionalists' findings because the features that are considered to be obstacles to an integration of interactional phenomena into grammar by grammarians are held to be defining of talk-in-interaction, i.e., attested conversation in real-life social action by interactionalists. In particular, the turn-taking system, which organizes the construction of units larger than individual utterances in interaction, is a pivotal 
organizing principle (Sacks et al., 1974). Units are often re-evaluated and elaborated on during their production, based on the communication partners' contributions (e.g., Hopper, 2008, 2011). Furthermore, speech production is on-line and timing is crucial (Auer, 2009). Finally, and most importantly, the meaning of an expression is interactively construed, and the meaning range of each expression is considered to be a social, rather than cognitive, product (Schegloff, 2005). Because of these constitutive features of spoken interaction, interactionalists are generally rather hesitant to formalize interactional findings in a grammatical framework (e.g., Barth-Weingarten, 2006; Deppermann, 2006, 2007; Imo, 2007, 2008; Günthner, 2008; Auer \& Pfänder, 2011).

For many of these problems, the cognitively oriented versions of Construction Grammar do in fact offer solutions, and thus many of the issues previously raised may rest on misconceptions about basic premises of cognitive approaches to language in general and Construction Grammar in particular. A considerable obstacle for a fruitful integration of interaction and grammar are, however, the different roles assigned to cognition in the two approaches, and clarifying these differences will be mandatory before real progress can be made.

The procedure taken in this study is to consider an interactional phenomenon studied in the most prominent interactional approach in this research area, Conversation Analysis (CA), and to ask how this phenomenon might be represented within Construction Grammar. After appreciating the minute detail a CA analysis produces, I will argue that a grammatical perspective can add some important insights that a purely CA-based approach is bound to overlook, and thus clarify what a grammatical perspective can offer that an interactional perspective currently does not. Next, I address apparent problems and show how they can be solved, before turning to a more fundamental problem, the roles of cognition in the two disciplines. I will argue that while these differences are based on crucial methodological differences, understanding them better allows us also to create a bridge between conversation and grammar. To conclude, I will argue that the two approaches involved, Construction Grammar and CA, can jointly contribute to a more comprehensive understanding of the interactional phenomena in language.

\section{Conversation}

$\mathrm{CA}$ is an approach to analyzing real-life conversation that was developed in the sociological framework of ethnomethodology, its main aim being the identification of participants' social practices (e.g., Sacks et al., 1974; Sacks, 1984, 1992). Its most defining theoretical premises are the restriction to authentic, conversational data, the conception of language use as social action, and the attention (and restriction) to participant categories as the only explanatory concepts allowed in the description (Schegloff, 2005; 
Heritage, 2008; cf. Hutchby \& Wooffitt, 1998). That is, descriptive categories for the analysis of conversation need to be demonstrably categories to which the participants in interaction attend such that they are not carried into the description by the analyst. This attention is demonstrated by the analyst by means of detailed sequential analyses of all instances of a phenomenon in a corpus and by adapting the analysis to each example until the description accounts for all instances (cf. Schegloff, 1968). The results of such analyses are sequential patterns of talk-in-interaction which constitute recognizable practices for its members.

As an example of the kinds of findings CA produces, and in order to illustrate its procedure, in the following we shall consider a comprehensive conversation analytic investigation of a typical phenomenon of spoken interaction, the interjection $o h$, for which specific sequential patterns of use have been established. In several papers, John Heritage has presented analyses of the English interjection oh in various contexts that demonstrate the subtle interactional work speakers carry out using this interjection (Heritage, 1984, $1998,2002,2005)$. Using $o h$ as an example is additionally useful for our purposes because as a change-of-state token (Heritage, 1984, see below), oh has a cognitive meaning. It may thus illustrate the possible relationships between grammar as viewed in cognitive linguistics and conversation analysis in some depth.

In his first analysis, Heritage concentrates on oh after informings. He finds that "in proposing a change of state with the production of $o h$, recipients can confirm that, although they were previously uninformed on the matter at hand, they are now informed" (Heritage, 1984, p. 304). This is in contrast to receipt tokens such as yes and $u m-h m$, which avoid or defer treating prior talk as informative (p. 305). An example of oh after the informing act of another speaker is the following:

(1) Heritage (1984, p. 302)

J: I w'z j'st eh ringing up t'say I'll be comin' down inna moment,

(.)

$\rightarrow \quad$ I: $\quad$ Ohgh goo:d,

Heritage shows that these reactions to informings containing oh often co-occur with evaluatory statements; that is, "oh receipts are commonly combined with assessment components to give an oh-plus-assessment turn structure" (Heritage, 1984, p. 302), as in example (1); in addition, oh-P LU S - A S S E S S M E N T may occur with additional turn components, such as a question eliciting further information:

(2) Heritage (1984, p.303, ex. 9)

R: I fergot t'tell y' the two best things that happen' tuh me t'day.

$\rightarrow \quad \mathrm{C}$ : Oh super.=What were they 
Another example of such additional components that are questions is presented in (3):

(3) Heritage (1984, pp. 307-308, ex. 18)

$\mathrm{V}$ : And she's got the application forms.=

$\rightarrow \quad \mathrm{J}: \quad=$ Ooh:: so when is 'er interview d'd she sa[: $\underline{\mathrm{y}}$

V: $\quad$ [She

didn't u- Well u-she's gotta send their fo:rm $\downarrow$ back

Sh[e d'sn't know w]hen=

J: $\quad[$ o $\underline{\mathrm{h}::: \text { : }]}$

$\mathrm{V}: \quad=$ the [interview i : s [yet.]

J: $\quad$ [Oh it's just th' [fo:] $\quad$ rm, =

Here, the first occurrence of $o h$ is followed by a question which elicits further information.

Oh is thus "routinely used to receipt information" (Heritage, 1984, p. 311), as also the other uses of oh in example (3) illustrate. This also concerns the acceptance of counter-information, as in example (4):

(4) Heritage (1984, p. 312)

B: It looks like beef'n bean curd.

(1)

J: Well I wan' lots of beef.

D: I think it's pork.

$\rightarrow \quad$ B: Oh. Pork.

D: $\quad$ Mh hm

Oh can also occur in the context of other-initiated repair:

(5) Heritage $(1984$, p. 316)

A: Well who'r you workin' for.

B: .hhh Well I'm working through the Amfat Corporation.

A: The who?

B: Amfah Corpora[tion, T's a holding company.

$\rightarrow$ A: $\quad[\mathrm{oh}$

A: Yeah.

Here, similarly, oh is used to signal the receipt of the reformulation or other solution to the trouble source detected: "The producer of the repair initiation receipts the repair unit with $o h$, thereby proposing a change of state of information and, by implication, a resolution of the trouble previously heard” (Heritage, 1984, p. 316).

Heritage furthermore notes that repair receipts and receipts of the responses to understanding checks are very similar, and that oh occurs in a sequential structure that can be presented in the following way (Heritage, 1984, p. 319): 
A: repairable

B: repair initiation / understanding check

A: repair/confirmation/disconfirmation

B: oh-receipt

Thus, the lexical item oh may be part of highly schematized sequential structures in which it fulfils its particular functions. More generally, however, it serves as a display of understanding, such that $o h$ "generically proposes that its producer has undergone some kind of change of state" (Heritage, 1984, p. 324). This may concern the understanding of new information after informings as much as the receipt of a repair or of a confirmation or disconfirmation of an understanding check.

In addition, Heritage (1984) observes that oh occurs in recipient conduct after news announcements. By itself, oh does not invite the communication partner to elaborate on the news (p. 329), as the pause indicates in example (6):

(6) J: Oh (well) let's hope something comes o:f i[:t

I:

[Yes:

J: Mh: ['h

I: $\quad[\mathrm{Ye}[\mathrm{s}$

J: [Derek's ho:me?

$(0.5)$

I: Yo:ur De[rek.

J: $\quad$ YYe:s $\mathrm{m}[\mathrm{m}$

$\rightarrow \quad \mathrm{I}: \quad[\mathrm{Oh}:$

(.)

I: An' - is he a' ri:ght?=

$\mathrm{J}:=\mathrm{Oh}$ he's fi:ne...

Thus, it is usually "the 'oh'-producer who subsequently progresses the talk" (Heritage, 1984, p. 334); the occurrence of oh alone is perceived as notably incomplete.

In a later paper, Heritage (2002) shows that the use of $o h$ after assessments does not necessarily involve surprise (which is generally assumed; cf., for instance, the $O E D)$, as example (7) illustrates:

(7) Heritage (2002, ex. 8)

A: They keep 'im awful nice somehow

$\rightarrow \quad$ B: $\quad$ Oh yeah I think she must wash 'im every [week

A: $\quad$ [God-she must (h) wash 'im every day the way

he looks [to me

B: $\quad[\mathrm{I}$ know it 
In example (7), speaker B does not use $o h$ to indicate a change in information state, since the following turns show that she knew the information presented by her partner already. Instead, Heritage argues, oh signals epistemic independence of the listener's knowledge from the speaker's utterance if it occurs as a second after assessments. Thus, he proposes that oh functions as a marker of change of orientation here.

Examples (8), (9), and (10) also illustrate that surprise may not be at issue in these uses of $o h$ and that "oh-prefaced responses markedly indicate that the question to which they respond has occasioned a shift in the respondent's attention. The occurrences of $o h$ in the following examples are recurrently associated with inquiries that address 'known information' or other difficulties concerning the appositeness or relevance of a question, and in many cases, they are used to sanction this and other aspects of a question's inappositeness in an inexplicit yet marked fashion" (Heritage, 1998, p. 326).

(8) Heritage (2002, ex. 12)

Jon: We saw Midnight Cowboy yesterday - or [suh- Friday.

Eve: [Oh?

Lyn: Didyu s- you saw that, [it's really good.

Eve: [No I haven't seen it

Rae [sed it 'n she said she f- depressed her

(): $\quad[()$

Eve: ter[ribly

$\rightarrow \quad$ Jon: $\quad$ OOh it's terribly depressing.

$\rightarrow$ Lyn: $\quad$ OOh it's depressing.

(9) Heritage (1998, p. 295, ex. 5)

A: Are you a sociology major?

$\rightarrow$ B: Oh no no.

A: Gee, I didn't mean to be insulting.

$\rightarrow \quad$ B: Oh no, I didn't mean it in that way. Sosh majors can't work in the department. Think about what I do.

(10) Heritage (1998, p. 296, ex. 6)

Mum: wuh:-yih- (.) Are you teaching this week?

$\rightarrow \quad$ Les: Oh I don't know I never kn: $\underline{0}::[\mathrm{w}$

Mum:

$\left[{ }^{\circ}\right.$ Ri:ght. ${ }^{\circ}$

To sum up thus far, even though $o h$ indicates that the speaker is undergoing some change-of-state in many contexts, such that he or she signals that s/he has received something s/he didn't know before, oh may also be used when the information is in fact not new.

More recently, Heritage (2005) uses his previous investigations of $o h$ to address the relationship between conversation and cognition directly. He argues that $o h$ is 
not a S Y M P TOM of certain cognitive processes; that is, it does not mean that there is really a change of cognitive states in the speaker who is uttering $o h$. Instead, speakers can be shown to place $o h$ at interactionally relevant places, fulfilling certain interactional tasks. Examples that illustrate this claim are (11) and (12):

(11) Heritage (2005, p. 192)

Shi: .hh When do you get out. Christmas week or the week before Christmas.

Ger: Uh:mm two or three days before Ch[ristmas,]

$\rightarrow$ Shi: $\quad[\mathrm{O} h:$,

(12) Jen: Okay then I was asking and she says you're working tomorrow as well,

Ivy: Yes I'm supposed to be tomorrow yes,

$\rightarrow$ Jen: Oh:::

In these examples, the speakers of the utterances containing oh are unlikely to signal surprise or the undergoing of a real change of cognitive state since their partners merely confirm one of the two alternatives that the speakers had been setting out for them. Therefore, Heritage (2005, p. 191) argues that "oh production is more likely to be driven by the external demands of interaction rather than the internal pressures of cognitive expression". Yet even though these occurrences of oh may not be symptoms of cognitive processing, they still function as acknowledgements of information provided by the communication partner, i.e., as signals of a change of a cognitive state of the speaker. Heritage therefore concludes that "cognitive process is both represented and embodied in interaction" (p. 201).

To summarize, Heritage's analyses reveal, and in fact in much more detail than it could be presented here, a general meaning of $o h$ as a change-of-state token for a broad range of its uses; that is, the interactional analysis indicates that for a large subset of the data, there is a stable symbolic relationship between the form $o h$ and a particular meaning. Moreover, the analyses identify different turn-formats in which the interjection can occur, which are associated with certain functions $o h$ can fulfil. That is, in the analyses Heritage specifies the sequential contexts in which oh may be used and which are related to certain contextual interpretations of the change-of-state marker, the repair marker and the change-of-orientation marker. Together, the analyses also indicate what kinds of social actions participants use $o h$ in and how these social actions are organized to be recognizable to the co-participants.

\section{Gram mar}

In order to address the differences in orientation between a grammatical and an interactional description, let us start out by investigating to what extent 
Heritage's account of $o h$ is a grammatical description already. This will allow us to identify what a grammatical perspective has to offer in addition to a CA description.

\subsection{S I M I LARI T I E S}

Heritage's account provides an analysis of many uses of oh as a change-ofstate token; this corresponds to the sign-based view taken in Construction Grammar (henceforth $\mathrm{CxG}$ ): oh constitutes a stable form-meaning pair. ${ }^{1}$ Heritage's (2005) argument that $o h$ is not directly related to certain cognitive states but part of a highly functional discursive practice corresponds to the position taken in cognitive linguistics; in cognitive semantics, meaning is not taken to be a truthful rendering of certain events, either, but is understood as cognitive construal (e.g., Lakoff, 1987). Therefore, a cognitive analysis would also hold $o h$ to be a linguistic sign and not a symptom of a cognitive state of the speaker; that is, it would be understood as a particular way of categorizing experience. Drawing on Goffman (1978), Wilkins (1992, p. 148) addresses this point explicitly: "interjections [...] tend to be socially situated acts, even if they are not conventionally situated" and "the illocutionary purpose of emotive interjections is to show how the speaker feels at the exact moment of speaking (in a fashion that is conventional and appropriate to the situation at hand)" (p. 152). The use of the interjection $o h$ is therefore truly symbolic (cf. also Clark \& Fox Tree, 2002, for a similar discussion of the hesitation markers $u h$ and $u m$ ). Thus, Heritage's account is similar to the more cognitive-linguistically oriented approach to $\mathrm{CxG}$ based on the work by Langacker, Goldberg, and Croft with respect to the symbolic nature of the item under consideration.

Furthermore, Heritage's analyses offer descriptions of different turnformats, or structural contexts, in which oh can occur. Partly, these sequential contexts are already highly schematic, like, for instance, the repair contexts (Heritage, 1984, p. 319; see example (5) above), and partly they are more specific, being dependent on certain semantic features in the contexts, such as the speech act meaning ASSESSMENT as a contextual feature in the interpretation of "oh in assessments" (Heritage, 2002). These structural contexts can easily be understood to correspond to different constructions in which instances of $o h$ receive their concrete interpretations. This perspective corresponds to the constructionist's position that any construction "with unique, idiosyncratic morphological, syntactic, lexical, semantic, pragmatic,

[1] Different prosodic realizations that influence the interpretation oh receives in particular contexts may, however, also be taken into account (cf. Local, 1996; Reber, 2012). Yet how prosody and grammar can be taken to interact with each other is an unresolved question, which would go far beyond the scope of this paper. 
OR discourse functional properties must be represented as an independent node in the constructional network in order to capture a speaker's knowledge of their language" (Croft, 2001, p. 25; emphasis original).

It is therefore very easy to see how Heritage's results can be recast into a $\mathrm{CxG}$ account. Neglecting the fact that there are as yet no accepted means for representing interactional notions like turn-constructional units or transition relevance places (cf. Ford et al., 1996; Selting, 1996), the structural contexts identified for $o h$ can be presented, for $o h$-P LU S - A S S ES S M EN T after informings, for instance, as form-meaning pairs. The form component describes that oh occurs turn-initially before a TCU expressing an assessment and possibly an optional TCU eliciting further information. In addition, as Local (1996) has demonstrated, many of the patterns identified in Heritage (1984) are associated with relatively distinct prosodic features. The meaning component comprises then a representation of the speech act of the previous turn, which is some kind of informing, and a representation of the meaning of the turn containing oh, which signals a change-of-state, plus evaluation and an optional elaboration. Numerous recent studies in Interactional Linguistics make use of this correspondence between the structural contexts identified in CA and the open form and meaning sides of constructions by postulating constructions for stable patterns of interactional sequencing of different degrees of schematicity (e.g., Fischer, 2000, 2006a, 2006b, 2010; Deppermann, 2006, 2007, 2008; Imo, 2007, 2008; Birkner, 2008; Günthner, 2008). Whether all details from conversation analyses like Heritage's study can be cast into a grammatical description is of course open; for instance, a result such as that $o h$ by itself after news announcements is heard as 'notably incomplete' has no obvious account in a grammatical analysis. On the other hand, it remains open whether this finding is itself not part of knowledge about news pre-announcements, which generally come in a tripartite structure of preannouncement, receipt/evaluation, and request to tell, where all three social actions can be produced in various different ways (see, for instance, Levinson, 1983 , p. 350), and where the notable incompleteness of $o h$ is due to the expectation that after the receipt/evaluation there should be a request to tell.

In any case we can conclude that central aspects of $\mathrm{CA}$ results seem to be compatible with central notions held in $\mathrm{CxG}$.

\subsection{APPARENT DIFFERENCES}

However, there also seem to be differences between the results from a $\mathrm{CA}$ study such as Heritage's and a Construction Grammatical representation.

In particular, interactional linguists have voiced concerns with respect to the status of constructions in $\mathrm{CxG}$ (e.g., Imo, 2007; Günthner, 2008). They reject especially the seemingly fixed, static image of constructions 
as stable, context-free form-meaning combinations. For instance, Imo (2007, p. 36) criticizes the implicit assumption of $\mathrm{CxG}$ that constructions are distinct, unambiguous categories. Ford (2004) and Ono and Thomson (1996) also warn against the interpretation of conversational units as fixed and static: "[s]yntactic knowledge, then, cannot be just something static that speakers 'carry around in their heads', but must be understood in a much more dynamic way as a resource that guides the production and interpretation of utterances" (Ono \& Tompson, 1996, p. 90). This perspective is reiterated in a recent collection by Auer and Pfänder (2011) in which the authors, in particular Hopper (2011) and Pekarek-Döhler (2011), argue that 'constructions' are basically "the linguist's a posteriori interpretations of constructional schemata that are deployed by speakers on a moment-by-moment basis as solutions to recurrent needs in real time” (Pekarek-Döhler, 2011, p. 82).

The concern that constructions may be perceived as static units is, however, shared by many grammarians in cognitive linguistics. For instance, Langacker has pointed out repeatedly that he does not understand the schemata of Cognitive Grammar as fixed entities; rather, he assumes that all entities in Cognitive Grammar may be entrenched to different degrees and that they form networks representative of their usage: "linguistic units are not separate and independent with respect to one another; some units overlap with others or include them as components. And rather than being distinct from their instantiations, schemas are best envisaged as inherent aspects of the processing activity in which they reside. They are immanent in their instantiations in much the same way as that the schematic shape of letter inheres in all of its fonts" (2008, p. 217). While schematic and specific units thus form a dynamic network, individual exemplars, frequency, and processes like metaphor or analogy also play considerable roles in grammar (e.g., Abbot-Smith \& Tomasello, 2006; Zeschel, 2010; Wonnacott, Boyd, Thomson, \& Goldberg, 2012). Similarly, McClelland and Bybee (2007, p. 439) stress the gradient nature of grammatical knowledge; they hold that "productive patterns are built up from experience with exemplars of multiple types". Productivity, accordingly, is "the tendency for a pattern to apply to new forms" (p. 439). This "allows productivity to be a matter of degree" and "an empirical matter" which "should be handled with care" (p. 440). This concern is reflected in the discussion on the definition of constructions; in particular, while $\mathrm{CxG}$ initially based the definition of construction-hood on the criterion of non-compositionality (e.g., Goldberg, 1995, p. 4), more recent versions hold that constructions may also be entrenched patterns: "Any linguistic pattern is recognized as a construction as long as some aspect of its form or function is not strictly predictable from its component parts or from other constructions recognized to exist. In addition, patterns are stored as constructions even if they are fully predictable as long as they occur with sufficient frequency" (Goldberg, 2006, p. 5). 
Furthermore, the results from corpus-driven quantitative approaches to $\mathrm{CxG}$, as exemplified in collostructional analyses (Stefanowitsch \& Gries, 2003; cf. also Gries \& Stefanowitsch, 2004; Stefanowitsch \& Gries, 2005), indicate that, for instance, many verb-argument-structure construction combinations are informed by statistical probabilities instead of by exceptionless rules. The results of such analyses show to what extent certain lexical items are attracted to certain grammatical constructions, painting a picture of grammar as a complex network in which units are related to each other by means of characteristic statistical patterns comprising significant attraction and repulsion. Construction Grammar and Interactional Linguistics thus agree more on the dynamic nature of grammar than hitherto assumed.

Another suspected problem is that while CA is interested in situated, contingent social action, grammar regards linguistic units as removed from the social contexts of their use. However, $\mathrm{CxG}$ also understands the structures of a language as a toolbox to solve regularly occurring, real-life problems of real speakers (Fillmore, 1976, 1982); consequently, semantic and encyclopaedic knowledge are taken to be indistinguishable (Fillmore \& Atkins, 1992), and especially frame semantics (Fillmore, 1976) is intended to bridge the gap between utterance semantics and extralinguistic knowledge. Moreover, much of current work in $\mathrm{CxG}$ is based on corpuslinguistic studies, which often pay attention to register and dialect (e.g., Bresnan \& Hay, 2007; see also Birkner, 2008). Langacker, like Fillmore, holds that " $[\mathrm{t}]$ he mental construction of a language is itself grounded in social interaction and cultural attitudes" (Langacker, 2008, p. 217). In addition, constructions do not constitute fixed, context-free entities; instead, coercion effects can be observed, for example, between verbs and argument structure constructions (e.g., Michaelis, 2004; Fuhs, 2010), or between mass and count nouns and certain noun phrase constructions (Fillmore \& Kay, 1995), accounting for sentences like there was squirrel all over the road or I put three beers into the fridge. Coercion effects are, however, prime examples for context-sensitivity in grammar. So given the context-sensitivity of constructional meanings, the gradient nature of constructional units, and the probabilistic relationships between constructions, the reservations against $\mathrm{CxG}$ from the interactionalist perspective may in fact be more due to a misunderstanding of the positions of $\mathrm{CxG}$ than a theoretical incompatibility.

\subsection{WHAT GRAMMAR HAS TO OFFER}

Given the considerable similarities between the concerns of $\mathrm{CA}$ and $\mathrm{CxG}$, and the fact that most apparent problems could be solved, it is now time to see what grammar can offer that possibly exceeds the possibilities of a CA analysis. 
I suggest that a genuinely grammatical approach can add to the above CA analyses by Heritage in three different ways:

a. A Construction Grammatical approach can show generalizations across items and can thus help to identify the sources of certain interpretations. In particular, some of the interpretations that oh may receive in context may be due to the structural contexts in which oh occurs, rather than due to the item oh itself. In this case, it makes sense to assume that meanings are encoded in structural contexts, i.e., grammatical constructions, rather than in the linguistic item occurring in these constructions.

b. A grammatical approach can explain the relationships between the different readings. For instance, it can account for the relationship between $o h$ as a change-of-state token, as in Heritage (1984), and as a signal of changing orientation, as in Heritage (2002).

c. A Construction Grammatical perspective on the results of CA-analyses may also serve to get the thinking, feeling, and categorizing language user who makes choices, consciously or unconsciously, back into the picture, and thus to readdress the gap between the cognitive and the social.

Concerning (a), generalization across lexical items, I would like to argue that a grammatical perspective is one that is oriented to the meanings connected to the structures that may be schematic to different degrees, i.e., they generalize over particular instances.

The CA focus on individual discursive practices, valuable as it may be to tease out the particular functions of linguistic structures in context, disguises the fact that some of the interpretations proposed by an item in a sequential pattern may originate in the sequential structure itself, rather than in the item under consideration. In particular, oh occurs in contexts in which other discourse markers may also occur. For instance, similar to example (1), we can find in the British National Corpus:

(13) $<$ PS6NM > : okay right so best of luck to you anyway if you $<$ PS6NN $>$ : [... ] okay

$<$ PS6NM $>$ : sort of get that er sort of er get a, a neat copy run off we might be able to get it down for repro to reprographics in time for er Tuesday week with a bit of luck

$<$ PS6NN $>$ : That should be no problem at all.

$\rightarrow \quad<$ PS6NM $>$ : Yeah good.

(14) $<$ PS2B2>: Aye I think they must it must be talking about dictating as well.

$<$ PS2B3 $>$ : down and sit writing long hand?

$<$ PS2B2>: No. No I think they'll mean it's number of stamps.

$<$ PS2B3 $>$ : Cos I rarely ever do that. 
$<$ PS2B2 $>$ : I think it's they look for the number of stamps used rather if it's what you

$\rightarrow \quad<$ PS2B3 $>$ : Ah well good.

(15) $<$ PS149>: I can sit in the smoking section [ ... ] with you?

$\rightarrow \quad<$ PS147>: Mm mm ... Good!

The interpretation that $o h$ serves to indicate a change of state in response to the partner's turn may thus come from the sequential context itself, not from a discursive practice developed around $o h$. That is, although $o h$ differs from the other lexical items used in the same slot, i.e., turn-initial before an assessment, because of its symbolic meaning (cf. Fischer, 2000), its occurrence in example (1) is similar to examples (13)-(15) in that all markers in this position acknowledge the partner's turn by signalling successful perception and understanding and continued attention, as well as a continuation of the same topic (Allwood, Nivre, \& Ahlsén, 1992); i.e., they claim that the current utterance relates relevantly to the previous (cf. Fischer, 2010). These meaning aspects are part of the constructional meaning; that is, the locus of the interpretations arising lies in the turn-initial occurrence of the respective discourse marker followed by an assessment. The interpretations are thus not connected to the discourse markers themselves, since in other contexts these discourse markers do not have these meanings (cf. also Fischer, 2006a), as the broad spectrum of uses of oh identified by Heritage in his various papers indicates. These constructional meanings, however, only become apparent if several linguistic items in the same structural contexts are considered and a grammatical perspective on the phenomena is taken (cf. also Deppermann, 2008). Taking the broader perspective produces a truly Construction Grammatical understanding of the data. Thus, taking G R A M M A R seriously means to provide for schematization and to account for the learnability of finite resources, and taking CONSTRUCTION GRAMMAR seriously means to allow for the possibility that certain meanings are carried by a construction, and not by a lexical item.

$\mathrm{CxG}$ does not necessarily postulate maximal generalizability; "maximally general categories and rules are highly likely not to be psychologically real" (Croft, 2001, p. 5); the identification of grammatical constructions is rather taken to be eventually the result of psychological research into categorization and the formation of taxonomies (p. 53). Furthermore, $\mathrm{CxG}$ foresees the possibility that there are inter-individual differences between the kinds of generalizations made (cf. Dabrowska, 2010). The problem of generalization and the postulation of categories constitutes a problem both for cognitive linguists and interactionalists; while CA focuses on participant categories only, cognitive linguists have to reject distributional analyses as well since there are no a priori criteria to decide which criteria are relevant for category 
formation (Ch. 1.4-1.5). Nevertheless, type and token frequencies can serve as indicators for schematized constructions; in particular, high type frequency indicates that a general category can be assumed (Bybee, 2007; Croft, 2001, p. 28; Zeschel, 2010). With respect to the discourse particle construction suggested above, given its high type frequency, it is probable that speakers do generalize over the individual uses of discourse particles.

Concerning (b), possible relations between the readings of an item, I want to suggest that a cognitive linguistic perspective on the data as embraced by $\mathrm{CxG}$ reveals relationships between linguistic structures and items that otherwise remain opaque.

In Heritage's account, the different sequential patterns identified stand beside each other as if they were completely unrelated. A CA account offers no relationship whatsoever to explain why oh can mean change-of-state in one context and, say, change-of-orientation in another. However, in line with conjunctions, modals, and other discourse markers (Sweetser, 1990; Fischer, 2000, 2006a, 2007), the change-of-state indicated by oh may occur either in response to the subject matter reported on or in response to the speech act of bringing the subject matter up. Thus, the reason why oh can be used in examples like (7)-(9) above, in which the speaker obviously knows the matter presented already, is that it refers not to the matter presented, but to the fact T H A T it is presented; for instance, the fact that the communication partner does not know the information conveyed, as in (9) and (10), or that the speaker had to bring it up at all, as in (8). That is, the speaker does not acknowledge the receipt of certain information presented, but, for instance, the fact that it was uttered at all.

Let us consider example (7) again:

(7) A: They keep 'im awful nice somehow

$\rightarrow$ B: Oh yeah I think she must wash 'im every [week

A: [God-she must (h) wash 'im every day the way

he looks [to me

B: $\quad[\mathrm{I}$ know it

Here, oh does not indicate that the speaker has undergone a change of state, since she does not know anything now that she did not know before. Heritage therefore suggests that $o h$ functions to initiate a change in orientation of the subsequent talk. However, allowing the same $o h$ to refer not to the content of what is being said but to the speech act itself, i.e., the fact that the communication partner says what she says, the suggested homonymy of the two different uses of $o h$ changes into systematic polysemy, in line with conjunctions like but or so, which may vary along the same dimension (Sweetser, 1990; Fischer, 2000). The fact that this occurrence of oh leads to a change in orientation follows naturally from the general change-of-state meaning 
of oh (cf. also Clark \& Fox Tree, 2002, for a similar argumentation regarding the hesitation markers $u h$ and $u m$ ).

The fact that CA does not suggest such relationships itself is, of course, not accidental; instead, CA and cognitive linguistics differ considerably with respect to their understanding of the nature of the patterns described. This leads to (c), bringing those who produce the talk analyzed in CA back into the picture.

Cognitive linguistics developed in contrast to a view of grammar as independent of its use, i.e., as a representation of linguistic competence (Chomsky, 1965), and as a module independent from other cognitive capabilities or even embodiment (e.g., Wierzbicka, 1985; Lakoff, 1987; Lakoff \& Turner, 1989; Fillmore \& Atkins, 1992). Thus, the development of cognitive linguistics can be seen as an attempt to bringing the embodied subject and his or her sensemaking activities back into the description of language structure.

In cognitive linguistics, meaning is understood as cognitive construal, and language structure is taken to be motivated by the cognitive representation of embodied human subjects (Cruse \& Croft, 2004). More recently, cognitive linguistics focuses not only on the impact of cognition and embodiment on grammar, but also on aspects of usage and entrenchment (e.g., Langacker, 2008). Here, grammar functions as a cognitively motivated resource the speakers of a language make use of, understanding grammar as a symbolic resource for subjective construal.

$\mathrm{CA}$, in contrast, describes structural contexts as socially attended to practices (Schegloff, 2005; Heritage, 2010). Discursive practices constitute a social resource which is demonstrably oriented to by the participants; the conversation analysts' task thus consists in describing those practices to which speakers in conversation attend. The regularities observed may be violated, but then need to be accounted for; that is, speakers violating interactional norms need to provide explanations, i.e., present accounts of the deviation from the normative expectations (Heritage, 1988). Grammar, in this view, is thus a collection of normative resources attended to by the participants (cf. Auer, 2002).

While CA studies thus reveal what participants are really orienting to, the embodied thinking, feeling, and categorizing subjects with their agendas, experiences, and preferences disappear in CA accounts. This may be desirable from a sociological perspective (Schegloff, 2005), yet it fails to account for the processes of categorization to which participants can be shown to attend.

\section{Cognition}

While the differences suggested between $\mathrm{CxG}$ and $\mathrm{CA}$ considered above thus rest on a misunderstanding of (some, though admittedly not all) grammatical 
positions that have so far hindered a successful integration of grammatical and interactional analyses, I would like to argue that it is in particular incompatible perspectives on cognition that prevent a reinterpretation of results obtained by means of conversation analysis, such as Heritage's, in grammatical terms. Given the general compatibility between CA results and $\mathrm{CxG}$ accounts discussed above, I wish to argue that currently discrepant theoretical perspectives on the nature of cognition in language use prevent the ready integration of findings such as Heritage's in a $\mathrm{CxG}$. While these differences cannot (and perhaps even should not) be overcome easily, clarifying the sources of divergence facilitates a division of labour between the two approaches and thus encourages their collaboration.

In particular I want to suggest that the origin of CA in the social sciences, and particularly in ethnomethodology (Garfinkel, 1967), implies a view on cognition as a phenomenon that itself needs explanation. One reason for this is methodological: ethnomethodology focuses on speakers' own methods to signal to their interaction partners what they consider the current social action to consist in (Heritage, 2010). By focusing on participants' own understandings, conversation analysts resist carrying non-emic categories into the analysis (Schegloff, 2005), that is, categories that are based only on the analyst's understanding and are not interactionally relevant to the participants. CA therefore concentrates on what is observable in a conversation such that it leaves traces within the sequential organization of an interaction (Sacks, 1984) and, correspondingly, resists the use of cognitive concepts and explanations. The other reason concerns CA's research interests: since ethnomethodology is interested in uncovering people's own methods for social action, invoking cognition becomes an object of investigation to the extent that conversationalists make use of it themselves; for instance, Lynch and Bogen (2005, p. 227) state: "the concept of 'cognition' itself is likely to be dissolved in the course of the displacement from an abstract space of mental representation to a contexture of communicative practices."

In this context, Heritage's finding that oh carries out specific interactional work and does not constitute a response to, or accurate representation of, a prior cognitive state, is in line with the orientation of CA at uncovering social practices. From this perspective, the display of a change-of-state, for instance, does not necessarily need to be related to a corresponding cognitive phenomenon. The CA analysis thus rather addresses under which circumstances participants represent cognitive processes in interaction.

However, beside its role as a participant category in which cognition is represented by the interactants as a means to accomplish social action, there are various other possible roles cognition may play in language use. The most obvious is that people seem to be able to store, organize, and retrieve shared linguistic resources; for instance, Hopper (2011) argues that conversation consists 
of routinized patterns that speakers memorize and reuse. He illustrates this for a stretch of conversation for whose patterns he finds thousands or even millions of hits each in a simple Google search. Memorizing and retrieving these 'sedimented routines' are, however, cognitive capabilities. While Hopper argues that constructions are not "timeless entities that are fully present and complete, whose beginning, middle and end can be surveyed simultaneously" (p. 42), suggesting that they are not stored (and thus cognitive) units, his own results in fact demonstrate that they are. In addition, collaboration, which has been shown to be a ubiquitous and pervasive feature of conversation (e.g., Auer, 2005), presupposes that conversationalists are indeed able to project a unit's middle and end. Hopper's position is also in contrast to Auer's (2002) findings that both syntax and interaction rely on the capacity for projection. While CA aims to uncover interactants' own methods for making actions recognizable, grammatical constructions allow the co-participants to project the upcoming social action (Auer, 2002, 2005). That is, grammatical constructions represent interactants' linguistic methods for projecting social action.

Memory, retrieval, and projection are thus cognitive capabilities that constitute prerequisites to interactants collaborating on constructions, as shown, for instance, by Pekarek-Döhler (2011). Thus, in contrast to her conclusion, that constructions are post-hoc postulates by linguists, these constructions are attended to resources interactants make use of and expect to be shared by their co-conversationalists (cf. also Deppermann, 2008, who concludes that constructions constitute a shared resource for participants).

In addition to being represented in interaction by the participants themselves, and in addition to enabling the knowledge of linguistic resources, cognition furthermore plays considerable roles with respect to processes like generalization, categorization, and schematization. That is, the linguistic resources interactants make use of are abstractions over usage events, such that similar items are categorized into classes, for instance, and prefabricated structures develop open slots (e.g., Tomasello, 2003, for first language acquisition). Considerable work, especially in cognitive linguistics, has been carried out uncovering these kinds of processes (e.g., Lakoff, 1987), which constitute an essential feature of linguistic competence. In particular, units of grammar are "schematic relative to both the source events and the further events in which they figure. Once established, they function as templates in constructing and interpreting new expressions. The relationship they bear to the corresponding aspects of subsequent usage events amounts to categorization" (Langacker, 2008, p. 220). The more cognitively oriented versions of $\mathrm{CxG}$ especially understand the degree of schematization, just like any instance of categorization, to constitute an empirical problem (cf. Croft, 2001, p. 27). In this connection, Construction Grammarians see generalizations as solutions to recurrent tasks that individual speakers, or groups of speakers, 
create (cf. Dabrowska, 2010). Yet while most versions of $\mathrm{CxG}$ postulate both specific and schematic units to co-exist in the network that constitutes grammatical knowledge (Croft, 2001, p. 28; Langacker, 2008, p. 238), they all assume such schematization to occur. The generalization and schematization processes contribute to the organization of grammatical knowledge in a structured inventory of constructions, corresponding to the cognitive organization of linguistic structures, (Croft, 2001, p. 27; Langacker, 2008, pp. 8-9). Thus, a core feature of a grammatical perspective on language is to account for generalization.

Moreover, from the point of view of grammar the question arises how speakers come to choose one linguistic construction over another. Choice, however, is likely to rely at least partly on cognitive mechanisms, such as participants' personal agendas (e.g., Fischer, 2011), institutional purposes (Stivers, Mondada, \& Steensig, 2011), genre (e.g., Birkner, 2008), social status (e.g., Matsumoto, 2010), face (Brown \& Levinson, 1987), and many other partially social, partially cognitive factors. One cognitive factor whose impact has recently been demonstrated (Fischer, 2011, forthcoming) is the partner model; for instance, caregivers have been found to memorize not only which words a child already knows, but also which ones it is about to learn, and to adjust the length of their utterances accordingly (Roy, Frank, \& Roy, 2009). Thus, people can be shown to attend to knowledge about previous encounters with their communication partners and to reason about them.

The relationships between linguistic resources and cognition may consequently be manifold and highly complex; among these various possible relations $\mathrm{CA}$ is very well suited to shed light on cognition as a resource claimed and invoked by the participants themselves (cf. the papers in te Molder \& Potter, 2005). However, other kinds of cognition are relevant in the description of language use, too. The anti-cognitive stance, which is widely, yet unevenly, spread in CA and related disciplines (see the breadth of papers in te Molder \& Potter, 2005), is methodologically and empirically justified by the analysis of cognition as represented in talk-in-interaction by the participants themselves; for instance, conversation analysts demonstrate that there are numerous interactional functions of a phrase like $I$ think that have nothing to do with the speaker thinking something in terms of "a private life of the mind" (Edwards \& Potter, 2005, p. 254). Here, CA and related approaches (esp. discursive psychology) constitute an important methodological safeguard against too easy explanations based on stipulations of intentions and other non-observable cognitive processes. However, other kinds of cognitive processes have been shown to be relevant for language use, and a Construction Grammatical perspective is very well suited to address these processes. To this, CA could in fact contribute by allowing their notion of 'attention to' to be reinterpreted in cognitive terms, which, however, is rather controversial; for instance, Potter and te Molder (2005, p. 21) argue that 
'attention-to' should not be understood in cognitive terms, but rather as a "special kind of psychological reality - not one defined by in-the-head mental processes, but by the participants orienting practically in the course of ongoing interaction to the relevant features of the interaction". Notwithstanding this, much work in $\mathrm{CA}$ has in fact pointed to cognitive processes as attended to by the participants themselves. One example is Bilmes' (2009) analysis of taxonomic categorization, which he shows participants to collaborate on and negotiate in interaction. Another example is speakers' attention to constituent boundaries (cf., for instance, Ford et al., 1996) and 'possible sentences' (Selting, 1996) in turntaking. Here, CA could contribute as an additional method to the empirical foundation of grammatical analysis. So while CA's methodological stance does not leave room for experimental studies like card sorting or reaction time tasks and is generally not the first choice of method that springs to mind for investigations of categorization, generalization, or schematization, there are in fact several studies using CA methodology that explicitly address categorization in interaction (cf. Schegloff, 2007).

Consequently, when conversation analysts hesitate to understand 'attention' in interaction as a cognitive process (see, for instance, Potter \& te Molder, 2005, pp. 20-21), then they do so on the basis of their findings on the representation of cognition in interaction, such as Heritage's results on $o h$ above that illustrate that its uses fulfil interactional functions rather than serve as expressions of cognitive processes. However, that displays of cognition cannot be taken as direct indicators of cognitive processing is a position held also in cognitive linguistics; it does not exclude that cognition generally plays numerous important roles in interaction. Consequently, conversation analysts' reservations against grammatical description based on a general anti-cognitivist stance are unwarranted and rely on a too narrow perspective on cognition in language.

\section{Conclusions and prospects}

In the course of this investigation, we have seen that $\mathrm{CxG}$ and $\mathrm{CA}$ are compatible in many respects, and that many aspects of the $\mathrm{CA}$ analyses presented can be easily transferred into a $\mathrm{CxG}$. In addition to being merely compatible, the two disciplines can profit from further collaboration. For instance, work in CA can provide grammarians with cognitively plausible descriptive categories to which participants demonstrably attend by uncovering the interactional consequences of a category evident in the sequential organization of the interaction. ${ }^{2}$

[2] In the same way, CA studies can also shed light on the interaction between grammar, prosody, and the lexicon; as Local (1996) shows, prosody may partly coincide with grammatical distinctions and partly be orthogonal to them. 
Furthermore, we have seen how certain requirements and perspectives from $\mathrm{CA}$ may make certain versions of $\mathrm{CxG}$ more suited for a representation of interactional phenomena than others. Thus, the integration of conversational features in a grammatical description favours a linguistic theory that sees grammatical knowledge as form-meaning pairs with a very wide conception of meaning, where the meanings are not taken to be direct reflections of cognitive processes but instead displays of cognition understood as social action. Finally, a grammatical representation to account for conversational phenomena will also have to resist any premature attempts at formalization, since traditional grammatical notions, such as sentence-hood, well-formedness, and semantic completion are not applicable to the description of conversational interaction.

To sum up, it seems that many of the suspected problems are not as problematic as suspected. However, we have also seen that a grammatical perspective would want to add further steps to the analysis of 'sedimented patterns' described by means of CA. These extra steps concern an account of generalization across items with a focus on identifying constructional meanings, an account of generalization across readings or constructions, such that the perceived relationship between different uses of the same lexical item would be represented in some way or other, and a cognitive perspective featuring the real, embodied, thinking and feeling speaker who is making linguistic choices. At the same time, $\mathrm{CxG}$ also profits from $\mathrm{CA}$ analyses in terms of realistic coverage and empirical support concerning the distinctions proposed by showing that participants in fact orient to them as well.

\section{REFERENCES}

Abbot-Smith, K., \& Tomasello, M. (2006). Exemplar-learning and schematization in a usagebased account of syntactic acquisition. Linguistic Review, 23, 275-290.

Allwood, J., Nivre, J., \& Ahlsén, E. (1992). On the semantics and pragmatics of linguistic feedback. Fournal of Semantics, 9, 1-26.

Auer, P. (2002). Projection in interaction and projection in grammar. InLiSt - Interaction and Linguistic Structures 33.

Auer, P. (2005). Projection in interaction and projection in grammar. Text, 25, 7-36.

Auer, P. (2009). On-line syntax: thoughts on the temporality of spoken language. Language Sciences, 31, 1-13.

Auer, P., \& Pfänder, S. (Eds.) (2011). Constructions: emerging and emergent. Berlin/Boston: de Gruyter.

Barth-Weingarten, D. (2006). fuzzy boundaries - Überlegungen zu einer Grammatik der gesprochenen Sprache nach konversationsanalytischen Kriterien. In A. Deppermann, R. Fiehler, \& T. Spranz-Fogasy (Eds), Grammatik und Interaktion (pp. 67-94). Mannheim/ Radolfszell: Verlag für Gesprächsforschung.

Bilmes, J. (2009). Taxonomies are for talking: reanalyzing a Sacks classic. Fournal of Pragmatics, 41, 1600-1610.

Birkner, K. (2008). Was X betrifft: Textsortenspezifische Aspekte einer Redewendung. In A. Stefanowitsch, \& K. Fischer (Eds.), Konstruktionsgrammatik II: Von der Konstruktion zur Grammatik (pp. 81-101). Tübingen: Stauffenburg. 
Bresnan, J. (2007). Is syntactic knowledge probabilistic? Experiments with the English dative alternation. In S. Featherston \& W. Sternefeld (Eds.), Roots: linguistics in search of its evidential base (Studies in Generative Grammar) (pp. 77-96). Berlin: Mouton de Gruyter.

Bresnan, J., \& Hay, J. (2007). Gradient grammar: an effect of animacy on the syntax of give in New Zealand and American English. Lingua, 118(2), 245-259.

Brown, P. \& Levinson, S. (1987). Politeness. Cambridge University Press.

Bybee, J. R. (2007). Frequency of use and the organisation of language. Oxford: Oxford University Press.

Chomsky, N. (1965). Aspects of the theory of syntax. Cambridge, MA: MIT Press.

Clark, Herbert H., \& Fox Tree, Jean E. (2002). Using $u h$ and $u m$ in spontaneous speaking. Cognition, 84, 73-111.

Croft, W. (2001). Radical Construction Grammar: syntactic theory in typological perspective. Oxford: Oxford University Press.

Cruse, D. A., \& Croft, W. (2004). Cognitive Linguistics. Cambridge: Cambridge University Press.

Dąbrowska, E. (2010). The mean lean grammar machine meets the human mind: empirical investigations of the mental status of linguistic rules. In H.-J. Schmid \& S. Handl (Eds.), Cognitive foundations of linguistic usage patterns: empirical approaches (pp. 151-170). Berlin: Mouton de Gruyter.

Deppermann, A. (2006). Construction Grammar - Eine Grammatik für die Interaktion? In A. Deppermann, R. Fiehler, \& T. Spranz-Fogasy (Eds.), Grammatik und Interaktion. Untersuchungen zum Zusammenhang von grammatischen Strukturen und Gesprächsprozessen (pp. 43-66). Radolfzell: Verlag für Gesprächsforschung.

Deppermann, A. (2007). Grammatik und Semantik aus gesprächsanalytischer Sicht. Berlin / New York: de Gruyter.

Deppermann, A. (2008). Lexikalische Bedeutung oder Konstruktionsbedeutungen? Eine Untersuchung am Beispiel von Konstruktionen mit verstehen. In A. Stefanowitsch \& K. Fischer (Eds.), Konstruktionsgrammatik II: Von der Konstruktion zur Grammatik (pp. 103-133). Tübingen: Stauffenburg.

Edwards, D., \& Potter, J. (2005). Discursive psychology, mental states and descriptions. In H. te Molder \& J. Potter (Eds.), Conversation and cognition (pp. 241-259). Cambridge: Cambridge University Press.

Fillmore, C. J. (1976). Frame semantics and the nature of language. In Annals of the New York Academy of Sciences: Conference on the Origin and Development of Language and Speech, 280, 20-32.

Fillmore, C. J. (1982). Frame semantics. In Linguistics in the morning calm (pp. 111-137). Seoul: Hanshin Publishing Co.

Fillmore, C. J., \& Atkins, B. T. (1992). Towards a frame-based lexicon: the case of RISK. In A. Lehrer \& E. F. Kittay (Eds.), Frames, fields, and contrasts (pp. 75-102). Hillsdale, NJ: Erlbaum Publishers.

Fillmore, C. J., \& Kay, P. (1995). Construction Grammar: course materials. Available from Copy Central, Bancroft Avenue, Berkeley.

Fillmore, C. J., Kay, P., \& O'Connor, M. (1988). Regularity and idiomaticity in grammatical constructions: the case of let alone. Language, 64(3), 501-538.

Fischer, K. (2000). From cognitive semantics to lexical pragmatics: the functional polysemy of discourse particles. Berlin / New York: Mouton de Gruyter.

Fischer, K. (2006a). Frames, constructions, and invariant meanings: the functional polysemy of discourse particles. In K. Fischer (Ed.), Approaches to discourse particles (pp. 427-448). Amsterdam: Elsevier.

Fischer, K. (2006b). Konstruktionsgrammatik und Interaktion. In K. Fischer \& A. Stefanowitsch (Eds.), Konstruktionsgrammatik: Von der Anwendung zur Theorie (pp. 133-150). Tübingen: Stauffenburg.

Fischer, K. (2007). Grounding and common ground: modal particles and their translation equivalents. In A. Fetzer \& K. Fischer (Eds.), Lexical markers of common grounds (Studies in Pragmatics 3) (pp. 47-66). Amsterdam: Elsevier. 


\section{F I S C HER}

Fischer, K. (2010). Beyond the sentence: constructions, frames and spoken interaction. Constructions and Frames, 2(2), 185-207.

Fischer, K. (2011). Interpersonal variation in understanding robots as social actors. In Proceedings of HRI'11, March 6-9th, 2011 (pp. 53-60), Lausanne, ACM Digital Library.

Fischer, K. (forthcoming). Designing speech for a recipient: the roles of partner modeling, alignment and feedback in so-called 'Simplified Registers'. Amsterdam: John Benjamins.

Ford, C. (2004). Contingency and units in interaction. Discourse Studies, 6(1), $27-52$.

Ford, C. E., Fox, B. A., \& Thompson, S. A. (1996). Practices in the construction of turns: the 'TCU' revisited. Pragmatics, 6(3), 427-454.

Fried, M., \& Östman, J.-O. (2005). Construction Grammar and spoken interaction: the case of pragmatic particles. Fournal of Pragmatics, 37(11), 1752-1778.

Fuhs, S. (2010). The force dynamics of English complement clauses. In D. Glynn \& K. Fischer (Eds.), Quantitative methods in cognitive semantics: corpus-driven approaches (pp. 137-154). Berlin / New York: Mouton de Gruyter.

Garfinkel, H. (1967). Studies in ethnomethodology. Englewood Cliffs, NJ: Prentice Hall.

Goffman, E. (1978). Response cries. Language, 54, 787-815.

Goldberg, A. E. (1995). Constructions: a Construction Grammar approach to argument structure. Chicago: University of Chicago Press.

Goldberg, A. E. (2006). Constructions at work: the nature of generalization in language. Oxford: Oxford University Press.

Goldberg, A. E. (2009). The nature of generalization in language. Cognitive Linguistics, 20(1), 93-127.

Gries, S., \& Stefanowitsch, A. (2004). Extending collostructional analysis: a corpus-based perspective on 'alternations'. International Fournal of Corpus Linguistics, 8, 31-61.

Günthner, S. (2008). Die 'die Sache/das Ding ist'-Konstruktion im gesprochenen Deutsch - eine interaktionale Perspektive auf Konstruktionen im Gebrauch. In A. Stefanowitsch \& K. Fischer (Eds.), Konstruktionsgrammatik II: Von der Konstruktion zur Grammatik (pp. 157-178). Tübingen: Stauffenburg.

Heritage, J. (1984). A change-of-state token and aspects of its sequential placement. In J. Atkinson \& J. Heritage (Eds.), Structures of social action: studies in Conversation Analysis (pp. 299-345). Cambridge: Cambridge University Press.

Heritage, J. (1988). Explanations as accounts. In C. Antaki (Ed.), Analysing everyday explanation: a casebook of methods (pp. 127-144). Thousand Oaks, CA: Sage Publications.

Heritage, J. (1998). Oh-prefaced responses to inquiry. Language in Society, 29, 291-334.

Heritage, J. (2002). Oh-prefaced responses to assessments: a method of modifying agreement/ disagreement. In C. Ford, B. Fox, \& S. Thompson (Eds.), The language of turn and sequence (pp. 196-224). New York: Oxford University Press.

Heritage, J. (2005). Cognition in discourse. In H. te Molder \& J. Potter (Eds.), Conversation and cognition (184-202). Cambridge: Cambridge University Press.

Heritage, J. (2008). Conversation Analysis as social theory. In B. Turner (Ed.), The new Blackwell companion to social theory (pp. 300-320). Oxford: Blackwell.

Heritage, J. (2010). Conversation Analysis: practices and methods. In D. Silverman (Ed.). Qualitative sociology, 3rd ed. (pp. 208-230). London: Sage.

Hopper, P. (2008). Die Bedeutsamkeit der mündlichen Interaktion für die Linguistik: Die Pseudocleft-Konstruktion im Englischen. In A. Stefanowitsch \& K. Fischer (Eds.), Konstruktionsgrammatik II: Von der Konstruktion zur Grammatik (pp. 179-188). Tübingen: Stauffenburg Verlag Brigitte Narr.

Hopper, P. (2011). Emergent grammar and temporality in interactional linguistics. In P. Auer \& S. Pfänder (Eds.), Constructions: emerging and emergent (pp. 22-44). Berlin/Boston: de Gruyter.

Hopper, P., \& Thompson, S. (2008). Projectability and clause combining in interaction. In R. Laury (Ed.), Crosslinguistic studies of clause combining: the multifunctionality of conjunctions (pp. 99-123). Amsterdam: John Benjamins.

Hutchby, I., \& Wooffitt, R. (1998). Conversation Analysis: principles, practices and applications. Cambridge: Polity Press. 
Imo, W. (2007). Der Zwang zur Kategorienbildung: Probleme de Anwendung der Construction Grammar bei der Analyse gesprochener Sprache. Gesprächsforschung, 8, 22-45.

Imo, W. (2008). Individuelle Konstrukte oder Vorboten einer neuen Konstruktion? Stellungsvarianten der Modalpartikel halt im Vor- und Nachfeld. In A. Stefanowitsch \& K. Fischer (Eds.), Konstruktionsgrammatik II: Von der Konstruktion zur Grammatik (pp. 135-156). Tübingen: Stauffenburg.

Kay, P. (1995). Construction Grammar. In J. Verschueren, J. Östman, J. Blommaert \& C. Bulcaen (Eds.), Handbook of pragmatics (pp. 171-177). Amsterdam/Philadelphia: John Benjamins.

Kay, P. (2006). Pragmatic aspects of grammatical constructions. In L. Horn \& G. Ward (Eds.), Handbook of pragmatics (pp. 675-700). Malden, MA: Blackwell.

Kay, P., \& Fillmore, C. J. (1999). Grammatical constructions and linguistic generalizations: the What's $X$ doing $Y$ ? construction. Language, 75(1), 1-33.

Kay, P., \& Michaelis, L. A. (2012). Constructional meaning and compositionality. In C. Maienborn K. von Heusinger, \& P. Portner (Eds.), Semantics: an international handbook of natural language meaning (pp. 2271-2296). Berlin: Mouton de Gruyter.

Lakoff, G. (1987). Women, fire, and dangerous things: what categories reveal about the mind. Chicago: University of Chicago Press.

Lakoff, G., \& Turner, M. (1989). More than cool reason: a field guide to poetic metaphor. Chicago: University of Chicago Press.

Langacker, R. W. (1987). Foundations of Cognitive Grammar, vol. 1: theoretical prerequisites, Stanford: Stanford University Press.

Langacker, R. W. (2008). Cognitive Grammar: a basic introduction. New York: Oxford University Press.

Levinson, S. C. (1983). Pragmatics. Cambridge: Cambridge University Press.

Local, J. (1996). Conversational phonetics: some aspects of news receipts in everyday talk. In E. Couper-Kuhlen \& M. Selting (Eds.), Prosody in conversation (pp. 177-230). Cambridge: Cambridge University Press.

Lynch, M., \& Bogen, D. (2005). 'My memory has been shredded': a non-cognitive investigation of 'mental' phenomena. In H. te Molder \& J. Potter (Eds.), Conversation and cognition (pp. 226-240). Cambridge: Cambridge University Press.

Matsumoto, Y. (2010). Interactional frames and grammatical description. Constructions and Frames, 2(2), 135-157.

McClelland, J. L., \& Bybee, J. (2007). Gradience of gradience: a reply to Jackendoff. Linguistic Review, 24, 437-455.

Michaelis, L. (2004). Type shifting in Construction Grammar: an integrated approach to aspectual coercion. Cognitive Linguistics, 15(1), 1-67.

Michaelis, L., \& Lambrecht, K. (1996). Toward a construction-based model of language function: the case of nominal extraposition. Language, 72, 215-247.

Ono, T., \& Thompson, S. A. (1996). Interaction and syntax in the structure of conversational discourse. In E. Hovy \& D. Scott (Eds.), Discourse processing: an interdisciplinary perspective (pp. 67-96). Heidelberg: SpringerVerlag.

Pekarek-Döhler, S. (2011). Emergent grammar for all practical purposes: the on-line formatting of left and right dislocations in French conversations. In P. Auer \& S. Pfänder (Eds.), Constructions: emerging and emergent (pp. 45-87). Berlin/Boston: de Gruyter.

Potter, J., \& te Molder, H. (2005). Talking cognition: mapping and making the terrain. In H. te Molder \& J. Potter (Eds.), Conversation and cognition (pp. 1-56). Cambridge: Cambridge University Press.

Reber, E. (2012). Affectivity in interaction: sound objects in English. Amsterdam/Philadelphia: John Benjamins.

Roy, B., Frank, M., \& Roy, D. (2009). Exploring word learning in a high-density longitudinal corpus. In Proceedings of the 31st Annual Meeting of the Cognitive Science Society, Amsterdam.

Sacks, H. (1984). Notes on methodology. In John M. Atkinson \& John Heritage (Eds.), Structures of social action (pp. 21-27). Cambridge: Cambridge University Press.

Sacks, H. (1992). Lectures on conversation. Oxford: Blackwell. 
Sacks, H., Schegloff, E., \& Jefferson, G. (1974). A simplest systematics for the organization of turn-taking for conversation. Language, 50, 697-735.

Sag, I. A. (2007). Sign-Based Construction Grammar: an informal synopsis. Unpublished manuscript, Stanford University.

Schegloff, E. A. (1968). Sequencing in conversational openings. American Anthropologist, 70(6), 1075-1095.

Schegloff, E. A. (1996). Turn organization: one intersection between grammar and interaction. In E. Ichs, E. A. Schegloff, \& S. Thompson (eds.), Interaction and grammar (pp. 52-133). Cambridge: Cambridge University Press.

Schegloff, E. A. (2005). On integrity in inquiry ... of the investigated, not the investigator. Discourse Studies, 7(4/5), 455-480.

Schegloff, E. A. (2007). A tutorial on membership categorization. Fournal of Pragmatics, 39, $462-482$.

Selting, M. (1996). On the interplay of syntax and prosody in the constitution of turnconstructional units and turns in conversation. Pragmatics, 6(3), 357-388.

Stefanowitsch, A., \& Gries, S. T. (2003). Collostructions: investigating the interaction of words and constructions. In Proceedings of the $18 \mathrm{th}$ International Conference on Computational Linguistics 747-753. (pp. 747-753). ACM Digital Library.

Stefanowitsch, A., \& Gries, S. T. (2005). Co-varying collexemes. Corpus Linguistics and Linguistic Theory, 1(1), 1-46.

Stivers, T., Mondada, L., \& Steensig, J. (Eds.) (2011). Knowledge and morality in conversation: rights, responsibilities and accountability. Cambridge: Cambridge University Press.

Sweetser, E. (1990). From etymology to pragmatics. Cambridge: Cambridge University Press.

Tomasello, M. (2003). Constructing a language: a usage-based approach to child language acquisition. Cambridge, MA: Harvard University Press.

Thompson, S., \& Couper-Kuhlen, E. (2005). The clause as a locus for grammar and interaction. Discourse Studies, 7(4/5), 481-505.

te Molder, H., \& Potter, J. (Eds.) (2005). Conversation and cognition. Cambridge: Cambridge University Press.

Wide, C. (2009). Interactional Construction Grammar: contextual features of determination in dialectal Swedish. In A. Bergs \& G. Diewald (eds.), Context and constructions (Constructional Approaches to Language 9) (pp. 111-142). Amsterdam/Philadelphia: John Benjamins.

Wierzbicka, A. (1985). Lexicography and conceptual analysis. Ann Arbor: Karona.

Wilkins, D. P. (1992). Interjections as deixis. Fournal of Pragmatics, 18, 119-158.

Wonnacott, E., Boyd, J., Thomson, J., \& Goldberg, A. E. (2012). Input effects on the acquisition of a novel phrasal construction in five year olds. Fournal of Memory and Language, 66, 458-478.

Zeschel, A. (2010). Exemplars and analogy: semantic extension in constructional networks. In D. Glynn \& K. Fischer (Eds.), Quantitative methods in cognitive semantics: corpus-driven approaches (pp. 201-219). Berlin / New York: Mouton de Gruyter. 